\title{
DISTRIBUIÇÃO DA CONCENTRAÇÃO DE POTÁSSIO NO SOLO EM LISÍMETROS CULTIVADOS COM AMENDOIM
}

\author{
JARBAS H. MIRANDA ${ }^{1}$, LUÍS R. BÉRGAMO ${ }^{2}$, JOÃO B. R. DA S. REIS ${ }^{3}$, \\ DÉCIO E. CRUCIANI ${ }^{4}$, SERGIO N. DUARTE ${ }^{5}$
}

\begin{abstract}
RESUMO: A aplicação de fertilizantes na agricultura pode provocar uma dinâmica de solutos no solo abaixo da zona radicular, podendo, além de provocar prejuízos econômicos, contaminar águas subterrâneas. O presente trabalho teve como objetivo acompanhar o processo de deslocamento do íon potássio $\left(\mathrm{K}^{+}\right)$em lisímetros preenchidos com solo de textura arenosa e cultivado com amendoim (Arachis hypogaea L.), sob diferentes condições de atenuação da densidade de fluxo radiante, como a utilização de filmes plásticos com diferentes espessuras (100 e 150 micras). O deslocamento do íon potássio $\left(\mathrm{K}^{+}\right)$foi monitorado por extratores de solução instalados em diferentes profundidades (15 e $25 \mathrm{~cm}$ ), e o manejo da fertirrigação foi realizado com a utilização de tensiômetros. Concluiu-se que a baixa radiação solar incidente nos dois ambientes com coberturas plásticas afetou negativamente a produtividade do amendoim; o período em que o amendoim demanda maior quantidade de potássio ocorre dos 30 aos 55 dias após a semeadura; as plantas de amendoim não apresentaram deficiência nutricional com menor lixiviação de $\mathrm{K}^{+}$para as camadas mais profundas do solo; nos lisímetros com cobertura plástica de 100 e 150 micras, ocorreu maior concentração de $\mathrm{K}^{+}$na superfície do solo.
\end{abstract}

PALAVRAS-CHAVE: dinâmica de solutos, extrator de solução, fluxo radiante.

\section{DISTRIBUTION OF THE POTASSIUM CONCENTRATION IN SOIL WITH LYSIMETERS CULTIVATED WITH PEANUT}

\begin{abstract}
The application of fertilizers in agriculture produce some solute displacement below the root zone and this situation has provoked great impacts, besides the economic damages, causing groundwater contamination. The present work has as the objective of monitoring the displacement process of the potassium $\left(\mathrm{K}^{+}\right)$in lysimeters filled with soil, sandy texture and cultivated with peanuts (Arachis hypogaea L.) under different conditions of reducing solar radiation by using plastic films with different thickness $(100$ and $150 \mu)$. The potassium displacement was monitored by soil solution extractors installed in different depths $(15$ and $25 \mathrm{~cm})$ and the fertigation management was accomplished by tensiometers. It was concluded that low incident solar radiation in the two environments with plastic coverings negatively affected peanut's yield; the period that the peanut demands larger amount of potassium happens from 30 to 55 days after sowing; peanut plants did not present nutritional deficiency with a smaller leaching of $\mathrm{K}+$ for the deepest layers of soil; in the lysimeters with plastic covering of 100 and 150 micras occurred a larger concentration of $\mathrm{K}+$ in the soil surface.
\end{abstract}

KEYWORDS: solute dynamics, soil solution extractor, radiant flow.

\section{INTRODUÇÃO}

O cultivo do amendoim visa principalmente à obtenção de sementes destinadas à extração de óleo e também ao consumo in natura, torradas ou empregadas na confecção de doces. Atualmente,

\footnotetext{
${ }^{1}$ Prof. Associado, Departamento de Engenharia de Biossistemas, ESALQ/USP, Av. Pádua Dias, 11, Piracicaba - SP, Fone: (0XX19) 3429-4123, ramal: 210, jhmirand@esalq.usp.br.

${ }^{2}$ Eng ${ }^{\mathrm{o}}$ Agrônomo, Empresa Dedini, lrbergamo@gmail.com

${ }^{3}$ Pesquisador Doutor, EPAMIG/URENM, Nova Porteirinha - MG

${ }^{4}$ Prof. Titular, Departamento de Engenharia de Biossistemas, ESALQ/USP, Piracicaba - SP

${ }^{5}$ Prof. Associado, Departamento de Engenharia de Biossistemas, ESALQ/USP, Piracicaba - SP, snduarte@esalq.usp.br Recebido pelo Conselho Editorial em: 8-8-2008

Aprovado pelo Conselho Editorial em: 13-1-2010
} 
estuda-se o amendoim como sendo uma planta com potencial para o biodiesel, já que a semente possui alto teor de óleo, maior até mesmo que a soja (GONÇALVES et al., 2004).

As últimas safras de amendoim no Estado de São Paulo têm apresentado aumento de produção e pouca variação em relação à área plantada, indicando incrementos na produtividade média alcançada, baseada principalmente na introdução de novas tecnologias e proporcionando ganhos de qualidade e conquista do mercado externo. No entanto, observou-se que, na safra de 2006/2007, quando comparada à de 2005/06, houve uma redução de $23 \%$ na produção e de $12 \%$ na área plantada e, dessa forma, os incrementos em produtividade registrados em safras anteriores não foram mantidos (IEA, 2007).

É uma planta de baixa exigência nutricional e apresenta a seguinte ordem de absorção de elementos químicos: nitrogênio $(\mathrm{N})>$ potássio $\left(\mathrm{K}^{+}\right)>$cálcio $\left(\mathrm{Ca}^{2+}\right)$ (ressalta-se que o nitrogênio vem da associação simbiótica com a bactéria Rhizobium, que transforma o nitrogênio do ar $\left(\mathrm{N}_{2}\right)$ em amônia $\left(\mathrm{NH}_{3}\right)$, sendo esta, posteriormente, incorporada à planta sob forma de proteína) (MALAVOLTA, 1980).

Portanto, destacar aspectos de aplicação de fertilizantes e defensivos agrícolas tem a sua devida importância e, dessa forma, a compreensão do deslocamento de determinados íons no solo assume papel fundamental tanto para um manejo adequado quanto no auxílio na previsão de riscos de contaminação de águas subterrâneas, pois pode auxiliar na avaliação da ocorrência de sua lixiviação para camadas subsuperficiais (MIRANDA \& DUARTE, 2002).

Em clima seco, sabe-se que a irrigação aumenta consideravelmente a produtividade do amendoim. Já em climas úmidos, pode ocorrer um aumento muito pequeno ou nenhum incremento de produtividade quando se aplica a irrigação (CÂMARA et al., 1983).

Em termos de fertirrigação, segundo CLOTHIER (1984), a compreensão do transporte simultâneo de água e solutos, em duas ou três dimensões, a partir de uma fonte pontual, permite desenvolver estratégias eficientes, sendo importante no dimensionamento, operação e manejo da fertirrigação. De acordo com ZANINI (1991), o conhecimento da conformação dos bulbos para as diferentes condições de campo é muito importante para projetos de irrigação e para a prática da fertirrigação, e, de maneira geral, os locais de maiores concentrações de $\mathrm{K}^{+}$coincidem com os locais de maior valor de umidade do solo, evidenciando seu caminhamento por fluxo de massa.

O potássio exerce importantes funções reguladoras, participando na ativação de enzimas e no processo fotossintético em vários níveis (GIANELLO et al., 1995). Por ser um nutriente móvel, pode ser facilmente perdido ao longo do perfil do solo, sendo necessárias aplicações frequentes desse elemento.

Os mecanismos que controlam o transporte de potássio no solo são baseados na rápida troca com outros cátions no solo. Quando a quantidade de potássio no solo é relativamente pequena com relação à capacidade de troca de cátions, a adsorção é controlada principalmente pelas variações da concentração de potássio na solução do solo. Quando a concentração de potássio na solução do solo aumenta, a capacidade-tampão do potássio decresce, e a velocidade de transporte do potássio se incrementa. No período de máxima taxa de absorção de potássio pela planta, com alta demanda de potássio, este elemento deve ser suprido pela água de irrigação até que a concentração no solo seja suficiente (BAR-YOSEF, 1999). Por outro lado, a fertilização com potássio, quando adicionado via água de irrigação, geralmente não causa qualquer reação química adversa nas tubulações e emissores, mas pode causar precipitação de sais insolúveis se são misturados com outros fertilizantes. Por exemplo, se o nitrato de cálcio é misturado com sulfato de potássio, pode resultar em um sulfato de cálcio insolúvel (ROLSTON et al., 1986).

No que diz respeito à questão da radiação solar, atualmente existe no mercado grande quantidade de empresas fabricantes de filmes plásticos, com seus diferentes modelos em termos de aditivação, espessura, tamanho, etc. São diversos os aditivos utilizados na fabricação dos filmes plásticos, existindo os que protegem o material contra a ação dos raios ultravioleta e, também, os 
filmes com aditivos controladores da luz e da radiação, que influenciam no processo de fotossíntese e permitem a adequação das temperaturas (FACTOR et al., 2000).

As condições ambientais para a produção de amendoim, em São Paulo, são tipicamente tropicais, recomendando-se seu cultivo na época de verão (GODOY et al., 2003). Nessa época, ao meio-dia, a intensa radiação solar, associada ou não à alta temperatura e ao déficit de pressão, de vapor, poderia provocar fotoinibição dinâmica ou, eventualmente, crônica da fotossíntese. Entretanto, OLIVEIRA (1998), estudando os componentes do balanço de radiação solar sobre uma cultura de amendoim irrigado em Rodelas - BA, verificou que a ocorrência de irrigação produz imediata redução no fluxo de radiação refletida e, simultaneamente, um aumento no saldo de radiação solar na superfície.

Quando se cultiva em casa de vegetação, deve-se estar atento às diferenças provocadas no ambiente quando comparadas ao cultivo a céu aberto, principalmente no que diz respeito à temperatura, umidade do ar, radiação solar e, consequentemente, à evapotranspiração. Segundo FARIAS et al. (1993), a cobertura plástica da estufa altera o balanço de radiação e energético, em relação ao ambiente externo e, consequentemente, a evapotranspiração. O consumo de água no interior da casa de vegetação é possivelmente menor, principalmente pela atenuação que ocorre na irradiância incidente e na menor taxa de renovação do ar pelas plantas (ROBLEDO \& MARTIN, 1981; BURIOL et al., 1995).

Portanto, tendo em vista que todas essas variáveis, conjuntamente, afetam o sistema água-solo-planta-atmosfera-solutos, objetivou-se com o presente trabalho avaliar o processo de deslocamento do íon potássio $\left(\mathrm{K}^{+}\right)$em lisímetros cultivados com amendoim, sob diferentes efeitos de atenuação da densidade de fluxo radiante.

\section{MATERIAL E MÉTODOS}

O experimento foi conduzido nas dependências do posto agrometeorológico do Departamento de Engenharia de Biossistemas da Escola Superior de Agricultura "Luiz de Queiroz" ESALQ/USP, Piracicaba - SP, localizado nas coordenadas geográficas: 2242’30”S, 47³8'00”W e altitude de $546 \mathrm{~m}$.

O experimento foi dividido nas seguintes etapas: a) implantação do experimento; b) limpeza, preparo do solo, instalação dos extratores e plantio do amendoim; c) cálculo da lâmina de fertirrigação a ser aplicada; d) curva de calibração do íon potássio, e e) aplicação da solução de potássio.

\section{Implantação do experimento}

Foram utilizados, para a condução da pesquisa, doze lisímetros (caixas de eternit) com dimensões: 1,60 m de comprimento, 1,15 m de largura e altura de 0,7 $\mathrm{m}$ (volume de 1,288 $\mathrm{m}^{3}$ ). $\mathrm{O}$ espaçamento utilizado foi de 3,5 m entre as fileiras de quatro lisímetros e 0,7 m entre os lisímetros.

Para fins de atenuação da densidade de fluxo radiante (q), foram instaladas coberturas plásticas com diferentes espessuras (100 e 150 micras), sendo também considerado um ambiente com os lisímetros a céu aberto. Os dados de densidade de fluxo radiante foram determinados pela Estação Automática Meteorológica que está situada ao lado do experimento e por um luxímetro portátil que determina a luminosidade, sendo que esta foi convertida em densidade de fluxo radiante $\left(\mathrm{W} \mathrm{m}^{-2}\right)$, conforme VILLA NOVA et al. (2001). A disposição do experimento (distribuição dos lisímetros), bem como as coberturas plásticas, pode ser conferida pelas Figuras 1A e 1B. 


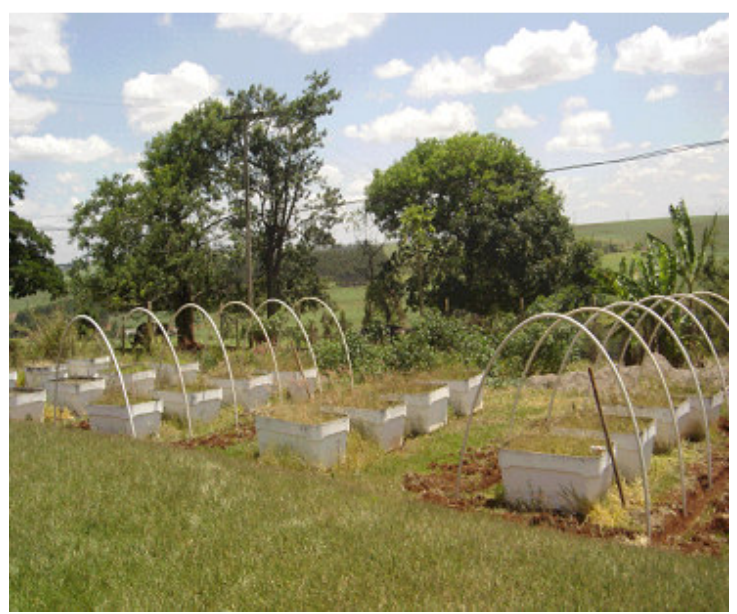

(a)

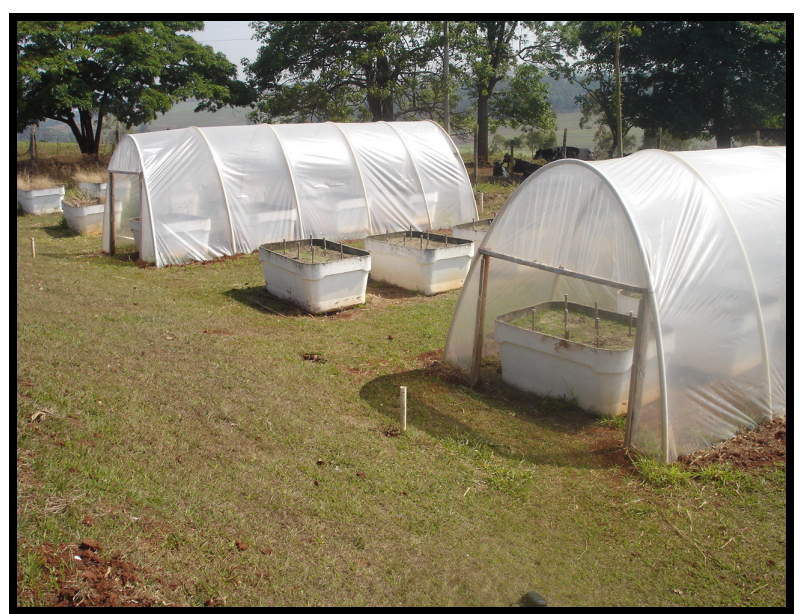

(b)

FIGURA 1. Disposição do experimento (distribuição dos lisímetros) (a) e coberturas plásticas no campo experimental do Departamento de Engenharia de Biossistemas (ESALQ/USP) (b). Experimental arrangement (lysimeter distribution) (a) and plastic covering in the experimental field of the Department of Biosystems Engineering (LEB) of the “Luiz de Queiroz” School of Agriculture, University of São Paulo (b).

O experimento foi delineado em faixas, com medidas repetidas ao longo do tempo, considerando-se três fatores de avaliação: 1) os ambientes, sendo dois deles diferenciados pela espessura do filme plástico e outro a céu aberto; 2) profundidades dos extratores de solução (15 e $25 \mathrm{~cm}$ ), e 3) 10 aplicações da solução de $\mathrm{K}^{+}$ao longo do ciclo. Em cada lisímetro, foram plantadas duas fileiras de plantio, sendo cada uma delas correspondente a uma repetição, considerando apenas o fator ambiente. As amostragens repetidas ao longo do tempo corresponderam a dois extratores instalados em cada lisímetro, instalados nas profundidades de $15 \mathrm{e}$ $25 \mathrm{~cm}$, espaçados de $57,5 \mathrm{~cm}$. Estes extratores contêm cápsulas porosas de cerâmica em sua extremidade inferior e borrachas especiais com vedação de silicone na extremidade superior.

\section{Limpeza e preparo do solo, instalação dos extratores e plantio do amendoim}

Após a limpeza, os lisímetros foram preenchidos com material de solo Argissolo Vermelho-Amarelo eutrófico abrúptico, textura arenosa (EMBRAPA, 1999). Em seguida, procedeu-se ao "revolvimento" do solo para deixá-lo em condições adequadas para o plantio.

Uma vez feito o preparo do solo, foram instalados os extratores de solução e tensiômetros, nas profundidades de 15 e $25 \mathrm{~cm}$. Após essas etapas de preparo, realizou-se o plantio do amendoim variedade IAC Tatu Vermelho, em janeiro de 2007, sendo dez plantas por metro linear, ficando cada lisímetro com aproximadamente 20 plantas. Na semeadura, colocou-se no sulco, junto com a semente, um inseticida para o controle da lagarta-rosca (Agrotis ipsilon). Utilizou-se também um fungicida para o tratamento de sementes, para controle de fungos de solo. Realizaram-se quatro aplicações foliares de fungicidas e inseticidas durante o ciclo do experimento.

Procedeu-se a uma amostragem do solo, para obtenção de suas características físicas (análise granulométrica e parâmetros fisico-hídricos do solo), antes do início do experimento, bem como uma análise química inicial. Tal procedimento foi feito retirando-se do solo a camada superficial de 0 a $20 \mathrm{~cm}$, procurando verificar a presença de macro e micronutrientes (Tabela 1). Em termos de características granulométricas, o material de solo apresentou as seguintes: $27 \mathrm{~g} \mathrm{~kg}^{-1}$ de argila, $78 \mathrm{~g} \mathrm{~kg}^{-1}$ de silte e $89 \mathrm{~g} \mathrm{~kg}^{-1}$ de areia. Com os resultados da análise (Tabela 1), realizaram-se cálculos para a estimativa da quantidade de adubo de que cada lisímetro necessitava. Dessa forma, foram aplicados em cada lisímetro: $45 \mathrm{~g}$ de superfosfato simples $\left(\mathrm{P}_{2} \mathrm{O}_{5}\right) ; 20 \mathrm{~g}$ de $\mathrm{KCl}$, aplicado via fertirrigação, numa concentração de $600 \mathrm{mg} \mathrm{dm}^{-3}\left(1,145 \mathrm{~g} \mathrm{~L}^{-1}\right)$ e $6,5 \mathrm{~g}$ de boro. 
TABELA 1. Análise química apresentando as concentrações de macro e micronutrientes analisados no material de solo. Chemical analysis showing the macro and micronutrients concentration analyzed in the soil material.

\begin{tabular}{|c|c|c|c|c|c|c|c|}
\hline \multicolumn{8}{|c|}{ Macronutrientes } \\
\hline $\begin{array}{c}\mathrm{pH} \\
\left(\mathrm{CaCl}_{2}\right)\end{array}$ & $\begin{array}{l}\text { M.O. } \\
\left(\mathrm{g} \mathrm{dm}^{-3}\right)\end{array}$ & $\begin{array}{c}\mathrm{P} \\
\left(\mathrm{mg} \mathrm{dm}^{-3}\right)\end{array}$ & $\begin{array}{c}\mathrm{K} \\
\left(\mathrm{mg} \mathrm{dm}^{-3}\right)\end{array}$ & $\begin{array}{c}\mathrm{Ca} \\
\left(\mathrm{mg} \mathrm{dm}^{-3}\right)\end{array}$ & $\begin{array}{c}\mathrm{Mg} \\
\left(\mathrm{mg} \mathrm{dm}^{-3}\right)\end{array}$ & $\begin{array}{c}\text { CTC } \\
\left(\mathrm{mmol}_{\mathrm{c}} \mathrm{dm}^{-3}\right)\end{array}$ & $\begin{array}{l}\mathrm{V} \\
(\%)\end{array}$ \\
\hline 5,0 & 14 & 26 & 58,64 & 561,09 & 97,22 & 37,5 & 52 \\
\hline \multicolumn{8}{|c|}{ Micronutrientes } \\
\hline \multirow{2}{*}{\multicolumn{2}{|c|}{$\begin{array}{c}\mathrm{B}\left(\mathrm{mg} \mathrm{dm}^{-3}\right) \\
0,19\end{array}$}} & $\mathrm{Cu}(\mathrm{mg}$ & \multicolumn{2}{|c|}{$\mathrm{Fe}\left(\mathrm{mg} \mathrm{dm}^{-3}\right)$} & $\mathrm{Mn}\left(\mathrm{mg} \mathrm{dm}^{-3}\right)$ & \multirow{2}{*}{\multicolumn{2}{|c|}{$\mathrm{Zn}\left(\mathrm{mg} \mathrm{dm}^{-3}\right)$}} \\
\hline & & 1,8 & & 07 & 2,3 & & \\
\hline
\end{tabular}

Foram realizadas 10 aplicações (fertirrigação), totalizando-se $12.000 \mathrm{mg} \mathrm{dm}^{-3} \mathrm{de} \mathrm{KCl}$ por lisímetro, o que correspondeu a aproximadamente $22 \mathrm{~g}$ de $\mathrm{KCl}$ por lisímetro.

Os parâmetros físico-hídricos do solo foram determinados mediante a elaboração da curva de retenção de água no solo pelo modelo de GENUCHTEN (1980), os quais foram calculados em função das necessidades hídricas do amendoim e obtidos para diferentes profundidades do perfil de solo (Tabela 2). A tensão crítica ou umidade crítica da cultura foi de $-0,04 \mathrm{MPa}$, a qual corresponde a uma umidade crítica de $0,25 \mathrm{~cm}^{3} \mathrm{~cm}^{-3}$.

TABELA 2. Parâmetros físico-hídricos do material de solo obtidos para diferentes profundidades do perfil de solo $(15 ; 30$ e $45 \mathrm{~cm})$. Soil-Water parameters of the soil material obtained for different depths in the soil profile $(15 ; 30$ and $45 \mathrm{~cm})$.

\begin{tabular}{llcl}
\hline \multirow{2}{*}{\multicolumn{1}{c}{ Parâmetros }} & \multicolumn{3}{c}{ Umidade Volumétrica $\left(\mathrm{cm}^{3} \mathrm{~cm}^{-3}\right)$} \\
\cline { 2 - 4 } & \multicolumn{3}{c}{ Profundidade $(\mathrm{cm})$} \\
\cline { 2 - 4 } & 0,190 & 0,195 & 45 \\
\hline Capacidade de Campo & 0,039 & 0,044 & 0,239 \\
Ponto de murcha permanente & 1,4 & 1,3 & 0,057 \\
Densidade do material de solo $\left(\mathrm{kg} \mathrm{dm}^{-3}\right)$ & 1,4 & 1,4 \\
\hline
\end{tabular}

\section{Cálculo da lâmina de fertirrigação a ser aplicada}

A lâmina calculada resultou em 12 litros da solução por fertirrigação, aplicados na fileira de plantio do amendoim. As aplicações foram realizadas de acordo com o turno de rega (dias), obtido em função da disponibilidade e capacidade hídrica do solo e da evapotranspiração da cultura [eq.(1)]. Como cada lisímetro apresentava duas fileiras, cada uma recebeu 6 litros de solução por irrigação, observando-se o turno de rega calculado de 5,7 dias.

$$
\mathrm{TR}=\frac{\left(\theta_{\mathrm{cc}}-\theta_{\mathrm{c}}\right) \mathrm{dzf}}{\mathrm{ET}}
$$

em que,

TR - turno de rega, dias;

Occ - umidade volumétrica na capacidade de campo, $\mathrm{cm}^{3} \mathrm{~cm}^{-3}$;

Өc - umidade crítica da cultura, $\mathrm{cm}^{3} \mathrm{~cm}^{-3}$;

$\mathrm{d}$ - densidade do solo, $\mathrm{kg} \mathrm{dm}^{-3}$;

$\mathrm{z}$ - profundidade do sistema radicular, $\mathrm{cm}$;

f - fator de necessidade hídrica da cultura, adimensional, e

ET - evapotranspiração do amendoim, $\mathrm{mm} \mathrm{dia}^{-1}$.

\section{Curva de calibração do íon potássio e aplicação da solução de potássio}

A curva de calibração do íon potássio foi feita a partir do reagente cloreto de potássio e utilizada para estimar o valor aproximado da concentração de potássio, auxiliando no monitoramento das leituras (Figura 2). Preparou-se uma solução-padrão de $12.000 \mathrm{mg} \mathrm{dm}^{-3} \mathrm{de} \mathrm{K}^{+}$ 


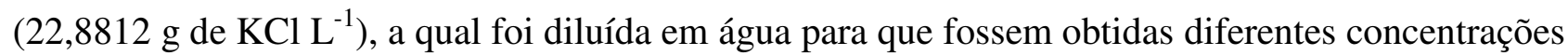
de potássio, cujos valores de condutividade elétrica foram medidos por um condutivímetro.

As aplicações de $\mathrm{K}^{+}$foram feitas vinte dias após a semeadura (tempo necessário para que todas as plantas emergissem), totalizando, durante o ciclo, 10 aplicações de $\mathrm{KCl}$. $\mathrm{O}$ momento das aplicações foi monitorado de acordo com as leituras dos tensiômetros. As soluções do solo foram retiradas dos extratores aproximadamente $24 \mathrm{~h}$ após a aplicação da solução de $\mathrm{K}^{+}$, sendo que, $\operatorname{logo}$ em seguida, efetuou-se o processo de vácuo nos extratores.

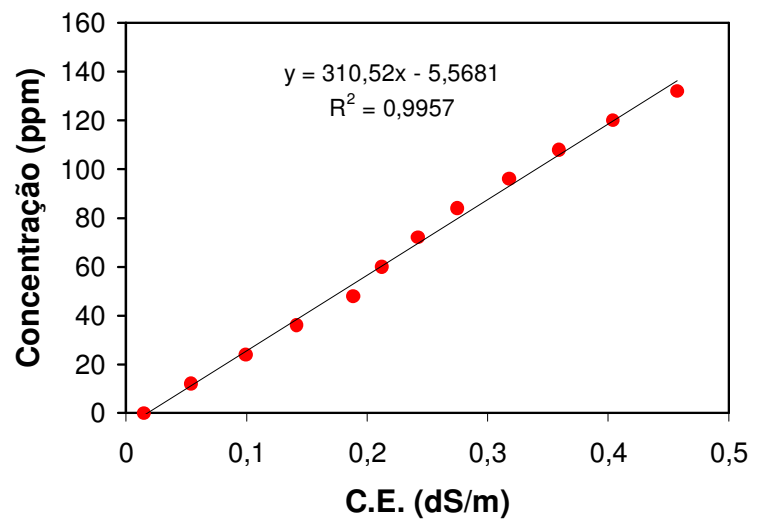

FIGURA 2. Curva de calibração do potássio feita com o condutivímetro. Potassium calibration curve done with the conductivimeter.

A colheita do amendoim foi realizada no dia 26-4-2007, 100 dias após a semeadura. Após $24 \mathrm{~h}$ secando ao ar livre para atingir a umidade ideal de armazenamento (5 a 7\% para o grão), o amendoim foi pesado e estimou-se a produtividade por hectare.

\section{RESULTADOS E DISCUSSÃO}

Pelos resultados obtidos, pôde-se verificar que, na profundidade de $15 \mathrm{~cm}$, houve maior concentração de íons $\mathrm{K}^{+}$em relação à profundidade de $25 \mathrm{~cm}$, para as diferentes coberturas plásticas e a céu aberto, sendo que, quanto maior a atenuação da densidade de fluxo radiante, maior era a concentração, evidenciando o caminhamento do íon potássio em função da umidade do solo. A razão da concentração de $\mathrm{K}^{+}$ser maior na profundidade de $15 \mathrm{~cm}$ também pode estar relacionada com a maior ocorrência de raízes das plantas do amendoim nos primeiros $20 \mathrm{~cm}$ do solo. Abaixo desta profundidade, a concentração de $\mathrm{K}^{+}$é menor devido ao fato de que as raízes absorveram grande parte do $\mathrm{K}^{+}$presente na solução do solo, havendo pouca ou nenhuma lixiviação deste elemento para camadas mais profundas. Na Figura 3A, mostra-se a curva de absorção de $\mathrm{K}^{+}$no solo, ou seja, a ocasião em que a planta de amendoim necessita de maiores quantidades de $\mathrm{K}^{+}$, cuja maior demanda ocorreu entre 30 e 50 dias após a semeadura (DAS), correspondendo ao período de florescimento e frutificação, segundo constatação de CÂMARA et al. (1983). O pico de absorção ocorreu aproximadamente aos 45 dias após a semeadura, conforme se pode observar nas profundidades de 15 e $25 \mathrm{~cm}$, onde a concentração de $\mathrm{K}^{+}$diminuiu pela metade (de 160 para $80 \mathrm{ppm}$ na profundidade de $15 \mathrm{~cm}$, e de 30 para $15 \mathrm{ppm}$ na profundidade de $25 \mathrm{~cm}$ ). A partir dos 55 dias após a semeadura, a absorção de $\mathrm{K}^{+}$começou a decrescer, entrando em processo de maturação, até cessar a absorção quase que completamente aos 82 dias após a semeadura.

Com a utilização da cobertura plástica de 100 micras, verificou-se que a concentração de $\mathrm{K}^{+}$ também foi maior na profundidade de $15 \mathrm{~cm}$ em relação à profundidade de $25 \mathrm{~cm}$ (Figura $3 \mathrm{~B}$ ). $\mathrm{O}$ pico de absorção de $\mathrm{K}^{+}$ocorreu também aproximadamente aos 45 dias após a semeadura, conforme se observa nas profundidades de $15 \mathrm{~cm}$ e $25 \mathrm{~cm}$, onde a concentração de $\mathrm{K}^{+}$diminuiu consideravelmente (de 150 para $70 \mathrm{ppm}$ na profundidade de $15 \mathrm{~cm}$, e de 30 para $15 \mathrm{ppm}$ na profundidade de $25 \mathrm{~cm}$ ). 
Em situações do plantio a céu aberto, verificou-se novamente que a concentração de $\mathrm{K}^{+}$foi maior na profundidade de $15 \mathrm{~cm}$ em relação à profundidade de $25 \mathrm{~cm}$ (Figura 3C). Abaixo desta profundidade, a concentração de $\mathrm{K}^{+}$foi menor devido ao fato de que as raízes absorveram grande parte dos íons $\mathrm{K}^{+}$presentes na solução do solo, o que ocorreu no trabalho de GIANELLO et al. (1995). A parcela conduzida a céu aberto recebeu maior quantidade de densidade de fluxo radiante (energia por unidade de tempo e área). Isto explica o fato de a concentração de $\mathrm{K}^{+}$na solução do solo ser menor quando comparada à solução do solo das parcelas sob a ação das coberturas plásticas de 100 e 150 micras.

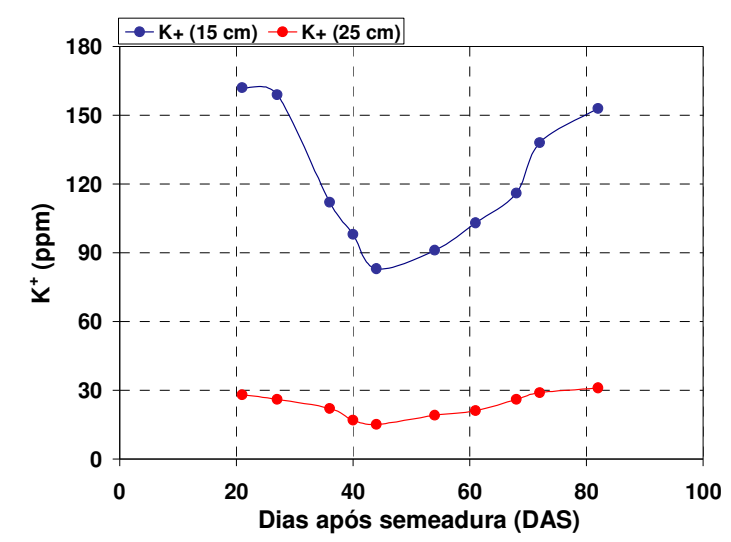

(a)

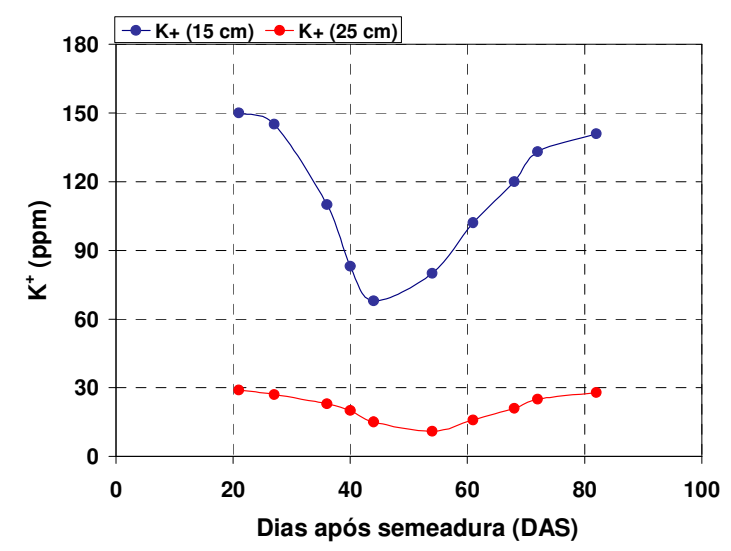

(b)

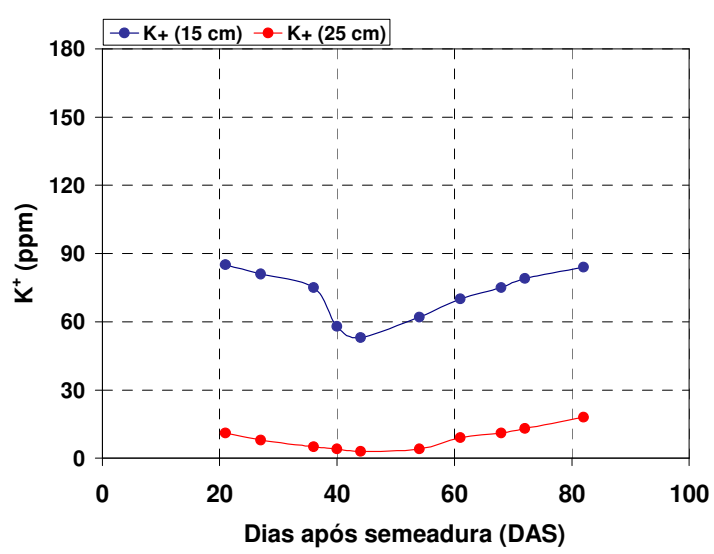

(c)

FIGURA 3. Valores de concentração do íon potássio ao longo dos dias após semeadura (DAS), para as profundidades de 15 e $25 \mathrm{~cm}$, sob a cobertura plástica de 150 micras (a); sob cobertura plástica de 100 micras (b), e sem cobertura plástica (c). Potassium concentration values along the days after sowing for the depths of 15 and $25 \mathrm{~cm}$, under the plastic covering of 150 micras (a), under plastic covering of 100 micras (b) and without plastic covering (c). 
Nos três ambientes estudados, foram observadas concentrações de potássio diretamente relacionadas com o valor encontrado pela análise química de macronutrientes (Tabela 1), sendo que $1,5 \mathrm{mmol}_{\mathrm{c}} \mathrm{dm}^{-3}$ equivale a $58,5 \mathrm{mg} \mathrm{dm}^{-3}$, valor condizente com a faixa ideal para potássio, no que

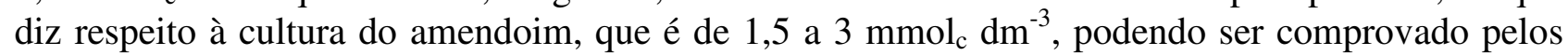
gráficos que evidenciaram a concentração de potássio nos diferentes ambientes.

Enfatizando a questão da quantidade de densidade de fluxo radiante incidente, em relação aos três ambientes estudados, observou-se que os valores da densidade de fluxo radiante incidente foram de $68 \%$ e $59 \%$, para as coberturas plásticas de 100 e 150 micras, em relação ao valor total para a condição de céu aberto. Na Figura 4, evidenciam-se esses valores de radiação incidente e mostra também que a maior quantidade do íon potássio ficou retida aos $15 \mathrm{~cm}$ de profundidade, em relação aos $25 \mathrm{~cm}$ de profundidade. Portanto, quanto maior a interceptação da energia radiante, maior a quantidade de potássio na parte superior do perfil do solo (BURIOL et al., 1995).

$\mathrm{Na}$ fase de desenvolvimento da planta, ocorreu aumento da quantidade de densidade de fluxo radiante, proporcionando elevada absorção de $\mathrm{K}^{+}$e aumentando a taxa fotossintética da planta (GODOY et al., 2003), a qual apresenta necessidade hídrica devido ao aumento de seu metabolismo.

Entre os 61 e 72 dias após a semeadura, o aumento da densidade de fluxo radiante diminuiu a absorção de $\mathrm{K}^{+}$, até a completa maturação dos frutos (momento da colheita), diminuindo sua necessidade hídrica. Aos 82 dias após a semeadura, a queda da densidade de fluxo radiante não alterou a absorção de $\mathrm{K}^{+}$, pois esta estava terminando seu processo de maturação, fase em que não absorve praticamente nenhum nutriente, já que sua necessidade hídrica é reduzida.

Em termos de produtividade, pôde-se observar que a parcela sem cobertura plástica obteve maior produtividade em relação às parcelas com cobertura plástica de 100 e 150 micras. Foram obtidos valores de $3.990,3.652$ e $3.553 \mathrm{~kg} \mathrm{ha}^{-1}$, sem cobertura plástica, com cobertura plástica de 100 micras e cobertura plástica de 150 micras, respectivamente.

Em relação à ação das coberturas plásticas, verificou-se que as plantas que estavam sob a cobertura plástica de 150 micras, produziram menos quando comparadas com as plantas que estavam sob a cobertura plástica de 100 micras. Essa menor produtividade da parcela com a cobertura de 150 micras é devida ao fato de que essa cobertura plástica provoca menor disponibilidade de energia radiante para a planta, de acordo com AYOADE (1998), provocando um maior estiolamento das plantas em relação à cobertura de 100 micras. 


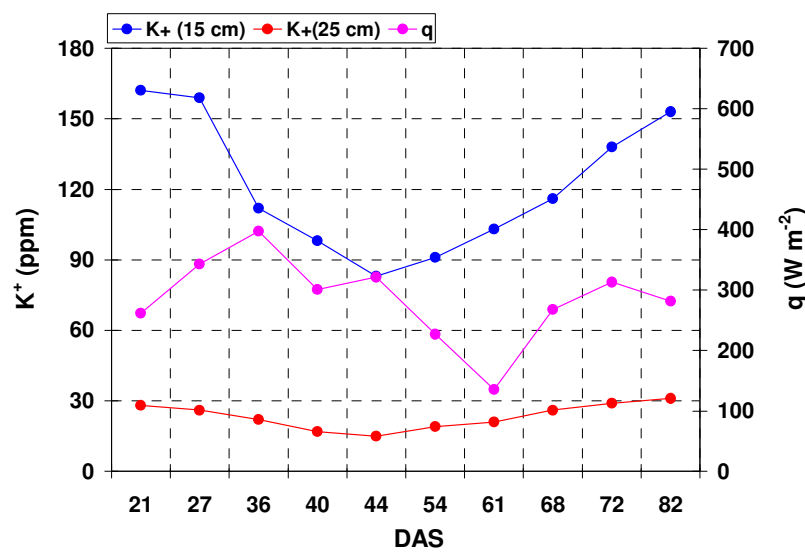

(a)

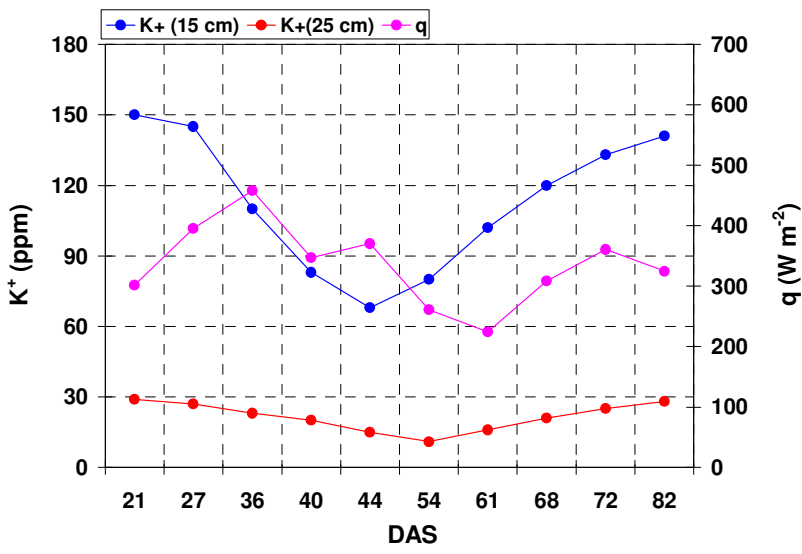

(b)

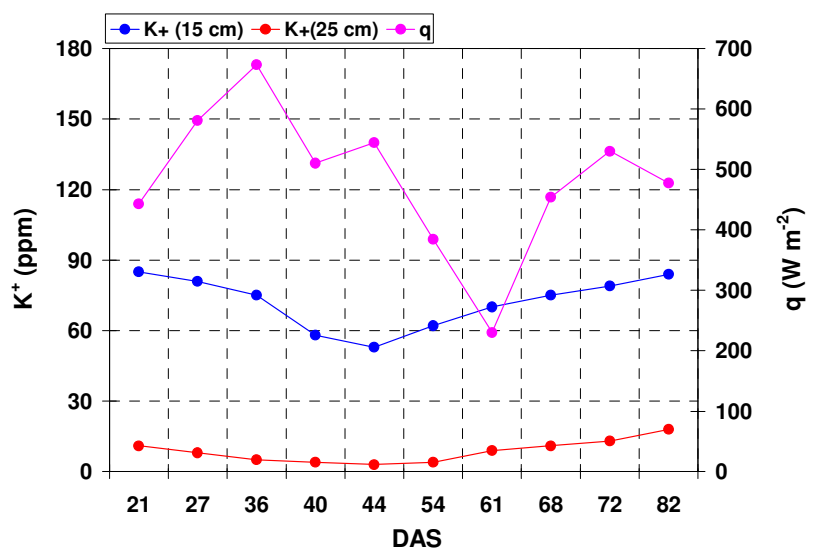

(c)

FIGURA 4. Concentração de potássio ao longo do DAS para as profundidades de $15 \mathrm{~cm}$ e $25 \mathrm{~cm}$, em relação à densidade de fluxo radiante (q), nas coberturas plásticas de 150 micras (a); 100 micras (b), e sem cobertura plástica (c). Potassium concentration values along the days after sowing for the depths of 15 and $25 \mathrm{~cm}$, in relation to the light flux density (q), under the plastic covering of 150 micras (a), 100 micras (b) and without plastic covering (c).

\section{CONCLUSÕES}

A baixa radiação solar incidente no interior das duas coberturas plásticas (100 e 150 micras) afetou negativamente a produtividade do amendoim.

O período em que o amendoim demanda maior quantidade de potássio ocorre dos 30 aos 55 dias após a semeadura.

As plantas de amendoim não apresentaram deficiência nutricional com menor lixiviação de $\mathrm{K}^{+}$para as camadas mais profundas do solo. 
Nos lisímetros com cobertura plástica de 100 e 150 micras, ocorreu maior concentração de $\mathrm{K}^{+}$ na parte superior do perfil de solo.

\section{AGRADECIMENTOS}

Ao $\mathrm{CNPq}$, pela concessão da bolsa de Iniciação Científica e apoio financeiro para a condução do experimento.

\section{REFERÊNCIAS}

AYOADE, J.O. O clima e a agricultura. In: . Introdução à climatologia para os trópicos. 5.ed. Rio de Janeiro: Bertrand Brasil, 1998. 332 p.

BAR-YOSEF, B. Advances in fertirrigation. Advances in Agronomy, New York, v.65, n.1, p.1-77, 1999.

BURIOL, G.A. de; STRECK, N.A. de; PETRY, C. de. Transmissividade à radiação solar do polietileno de baixa densidade utilizado em estufas. Ciência Rural, Santa Maria, v.25, n.1, p.1-4, 1995.

CÂMARA, G.M.S.; GODOY, O.P.; FILHO, J.M.; FONSECA, H. Técnica cultural. In:

Produção, pré- processamento e transformação agroindustrial. Piracicaba: FEALQ, 1983. p.1-38. (Série Extensão Agrícola, 3)

CLOTHIER, B.E. Solute travel times during trickle irrigation. Water Resources Research, Washington, v.20, n.12, p.1.848-1.852, 1984.

EMBRAPA. EMPRESA BRASILEIRA DE PESQUISA AGROPECUÁRIA. Sistema brasileiro de classificação dos solos. Rio de Janeiro: Embrapa - SPI, 1999. 412 p.

FACTOR, L.T.; ARAÚJO, J.A.C. de; CORTEZ, G.E.P. Comportamento da cultura do meloeiro em ambiente protegido com a utilização do filme térmico difusor de luz. In: CONGRESSO BRASILEIRO DE OLERICULTURA, 40., 2000, São Pedro. Resumos... São Pedro: SOB/FCAVUNESP, 2000. p.199-201.

FARIAS, J.R.B. de; BERGAMASCHI, H. de; MARTINS, S.R. de; BERLATO, M.A. Efeito da cobertura plástica de estufa sobre a radiação solar. Revista Brasileira de Agrometeorologia, Santa Maria, v.1, n.1, p.31-36, 1993.

GENUCHTEN, M. Th. Van. A closed-form equation for predicting the hydraulic conductivity of unsaturated soils. Soil Science Society of America Journal, Madison, v.44, n.5, p.892-898, 1980.

GIANELlO, C.; BISSANI, C. A.; TEDESCO, M. J. Princípios de fertilidade do solo. Porto Alegre: UFRGS/Departamento de Solos, 1995. 277 p.

GODOY, I.J. de; MORAES, S.A.; KASAI, F.S.; MARTINS, A.L.M.; PEREIRA, J.C.V.N.A.;

MORAES, A.R.A.; TEIXEIRA, J.P.F. Cultivares de amendoim IAC: novas opções para o mercado de confeitaria. Campinas: Instituto Agronômico, 2003. 10 p.

GONÇAVES, J.A.; PEIXOTO, C.P.; LEDO, C.A.S. Componentes de produção de amendoim em diferentes arranjos espaciais no Recôncavo Baiano. Revista Brasileira de Oleaginosas e Fibrosas, Campina Grande, v.8, n.2/3, p.801-812, maio/dez. 2004.

IEA. INSTITUTO DE ECONOMIA AGRÍCOLA. Amendoim: Perspectivas para a safra 2007/2008. Análise e Indicadores do Agronegócio, São Paulo, v.2, n.10, out. 2007.

MALAVOLTA, E. Elementos de nutrição mineral de plantas. São Paulo: Agronômica Ceres, 1980. $251 \mathrm{p}$. 
MIRANDA, J.H.; DUARTE, S.N. Modelo para simulação da dinâmica de nitrato em colunas verticais de solo não saturado. Revista Brasileira de Engenharia Agrícola e Ambiental, Campina Grande, v.6, n.2, p.235-241, 2002.

OLIVEIRA, G.M. Advecção sobre um cultivo de amendoim irrigado. 1998. 111 f. Dissertação (Mestrado em Irrigação e Drenagem) - Universidade Federal da Paraíba, Campina Grande, 1998.

ROBLEDO, F.P.; MARTIN, L.V. Applicación de los plásticos en la agricultura. Madrid: Mundi Prensa, 1981. $552 \mathrm{p}$.

ROLSTON, D.E.; MILLER, R.J.; SCHULBACH, H. Management principles: fertilization. In: NAKAYAMA, F.S.; BUCKS, D. Trickle irrigation for crop production design operation and management. Amsterdam: Elsevier, 1986. p.317-344.

VILLA NOVA, N.A.; SANTIAGO, A.V.; REZENDE, F.C. Energia solar: aspectos físicos e de captura pela biomassa. Piracicaba: ESALQ/USP/DCE, 2001. 20 p.

ZANINI, J.R. Distribuição de água e do íon $\mathrm{K}+$ no solo, aplicados por fertirrigação em gotejamento. II - Teores de K+ no bulbo molhado. Irrigação e Tecnologia Moderna, Brasília, v.46, n.1, p.24-38, 1991. 